\title{
Technical Note: Vapor pressure estimation methods applied to secondary organic aerosol constituents from $\alpha$-pinene oxidation: an intercomparison study
}

\author{
S. Compernolle, K. Ceulemans, and J.-F. Müller \\ Belgian Institute for Space-aeronomy, Ringlaan 3, 1180 Brussels, Belgium \\ Received: 19 March 2010 - Published in Atmos. Chem. Phys. Discuss.: 1 April 2010 \\ Revised: 30 June 2010 - Accepted: 5 July 2010 - Published: 9 July 2010
}

\begin{abstract}
We applied and compared seven vapor pressure estimation methods to the condensable compounds generated in the oxidation of $\alpha$-pinene, as described by the state-ofthe-art mechanism of the BOREAM model (Capouet et al., 2008). Several of these methods had to be extended in order to treat functional groups such as hydroperoxides and peroxy acyl nitrates. Large differences in the estimated vapor pressures are reported, which will inevitably lead to large differences in aerosol formation simulations. Cautioning remarks are given for some vapor pressure estimation methods.
\end{abstract}

\section{Introduction}

Biogenic SOA, originating from the oxidation of organic molecules such as isoprene and terpenes, is estimated to be a major contributor to organic aerosol (Hallquist et al., 2009). Many uncertainties exist regarding the formation and composition of SOA. These include, among others, missing pathways in the gas-phase oxidation of Volatile Organic Compounds (VOC) to semi- and nonvolatile ones, unmeasured vapor pressures of most relevant semi volatile molecules, illconstrained non-ideality effects due to the fact that SOA is a mixture, unknown heterogeneous and aerosol phase reactions, etc. If aerosol formation is primarily due to equilibrium partitioning, Pankow's formula (Pankow, 1994) applies (here written in its molar form; Compernolle et al., 2009; Barley et al., 2009)

$\frac{c_{p, i}}{c_{g, i}}=\frac{R T}{\gamma_{i} p_{i}^{0}} c_{o m}$

with $R$ the ideal gas constant, $T$ the temperature, $p_{i}^{0}$ the vapor pressure, and $\gamma_{i}$ the activity coefficient, $c_{p, i}$ and $c_{g, i}$

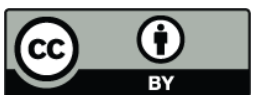

Correspondence to: S. Compernolle (steven.compernolle@aeronomie.be) the mole quantity of species $i$ per volume of air in aerosol phase and gas phase respectively, and $c_{o m}$ the mole quantity of SOA per volume of air. Both $\gamma_{i}$ and $p_{i}^{0}$ of a molecule determine its presence in the aerosol phase, but while $\gamma_{i}$ varies typically over an order of magnitude for a mixture of similar compounds (e.g. all originating from the oxidation of the same hydrocarbon; Compernolle et al., 2009), $p_{i}^{0}$ varies over many orders of magnitude. For the large majority of compounds contributing to SOA, no experimental $p_{i}^{0}$ is known and hence it has to be estimated.

Many methods for vapor pressure estimation have been developed. Some of them use only molecular structure, often in the form of a group contribution method, while others need also molecular properties as input, such as the boiling point. As these properties are unknown for most species, they have themselves to be estimated. Some methods (see e.g. Capouet and Müller, 2006; Pankow and Asher, 2008) assume a linear dependence of $\ln \left(p_{i}^{0}\right)$ on the number of functional groups, but this approximation fails especially when multiple hydrogen bonding groups are present. To counter this deficiency, other methods introduce group interaction terms (Nannoolal et al., 2008; Moller et al., 2008), but the number of different terms becomes very large in these methods and there is in general a lack of data for polyfunctional molecules to constrain them. Also the scaling of the group interaction with number of functional groups is not trivial, and this choice is important for highly polyfunctional molecules, as we will show in this work. The following methods are compared: the method of Capouet and Müller (2006) (CM), SIMPOL (Pankow and Asher, 2008), SPARC (Hilal et al., 2003), and three methods needing a boiling point as input (Myrdal and Yalkowsky, 1997; Nannoolal et al., 2008; Moller et al., 2008). The boiling point is estimated either with the old method of Joback and Reid (1987) or the more recent and detailed method of Nannoolal et al. (2004).

During the course of this work Barley and McFiggans (2010) made an assessment of different vapor pressure

Published by Copernicus Publications on behalf of the European Geosciences Union. 
Table 1. Overview of the seven different vapor pressure estimation methods used in this work.

\begin{tabular}{llll}
\hline Vapor pressure method & Boiling point method & abbreviation in text & mathematical symbol \\
\hline Capouet and Müller (2006) & N/A & CM & $p_{\mathrm{CM}}^{0}$ \\
Pankow and Asher (2008) & N/A & SIMPOL & $p_{\mathrm{SI}}$ \\
Hilal et al. (2003) & N/A & SPARC & $p_{\mathrm{SP}}^{0}$ \\
Myrdal and Yalkowsky (1997) & Joback and Reid (1987) & MY-JR & $p_{\mathrm{MY}}^{0}\left(T_{b, \mathrm{JR}}\right)$ \\
Myrdal and Yalkowsky (1997) & Nannoolal et al. (2004) & MY-Nan & $p_{\mathrm{MY}}^{0}\left(T_{b, \mathrm{~N}}\right)$ \\
Nannoolal et al. (2008) & Nannoolal et al. (2004) & Nan-Nan & $p_{\mathrm{N}}^{0}\left(T_{b, \mathrm{~N}}\right)$ \\
Moller et al. (2008) & Nannoolal et al. (2004) & Mol-Nan & $p_{\mathrm{M}}^{0}\left(T_{b, \mathrm{~N}}\right)$ \\
\hline
\end{tabular}

methods in their ability to predict vapor pressures of lowervolatility compounds, including all methods presented here except SPARC. Their study is complementary with the current work, as they compare the vapor pressure estimations with experimental values for compounds of relatively higher volatility. In this study, our focus will be on typical aerosol constituents predicted by the BOREAM model, for which experimental vapor pressures are generally not available. The impact of some of these methods in the simulation by BOREAM of SOA yields of $\alpha$-pinene dark-ozonolysis smog chamber experiments was very recently investigated by Ceulemans et al. (2010).

\section{Description of boiling point and vapor pressure esti- mation methods}

We tested in total seven different vapor pressure estimation methods, given in Table 1, together with the abbreviation used in this work. Some of them need only molecular structure as input while others are combined with a boiling point estimation method. The boiling point methods and vapor pressure methods are explained below. Note that the boiling point method of Nannoolal et al. (2004), and the vapor pressure methods of Myrdal and Yalkowsky (1997); Nannoolal et al. (2008); Moller et al. (2008) are available on-line at the E-AIM website (Extended Aerosol Inorganics Model, www.aim.env.uea.ac.uk/aim/ddbst/pcalc_main.php).

\subsection{Boiling point method of Joback and Reid (1987), and its extension}

Here it is assumed that the boiling point can be written as a sum over groups:

$T_{b, \mathrm{JR}}=198.2+\sum_{k} v_{k} \Delta T_{b, k}$

where $k$ runs over the groups, $v_{k}$ is the occurrence of this group in the molecule, and $\Delta T_{b, k}$ a contribution to the boiling point due to this group. The linearity assumption has been criticized before (e.g. Stein and Brown, 1994; Barley and McFiggans, 2010), in giving too high boiling points for large compounds. The Joback method should in principle only be applied to components within a certain boiling point range. Outside this range, a correction has to be applied that can be derived e.g. from a plot of estimated vs. experimental normal boiling temperature for a sufficient number of components. In the original method, no parameters are present for peroxide $(-\mathrm{OO}-)$, hydroperoxide $(-\mathrm{OOH})$, peracid $(-\mathrm{C}(=\mathrm{O}) \mathrm{OOH})$, nitrate $\left(-\mathrm{ONO}_{2}\right)$ and peroxy acyl nitrate $\left(-\mathrm{C}(=\mathrm{O}) \mathrm{OONO}_{2}\right)$ groups, which are all present in the BOREAM model. Decomposition is a problem for the direct determination of boiling points of hydroperoxides, peracids and peroxy acyl nitrates (Egerton et al., 1951; Kacmarek, 1978). Camredon and Aumont (2006) extended the Joback method for nitrates based on experimental boiling point data, and we take over this group-contribution value.

For peroxy acyl nitrates, Camredon and Aumont (2006) extended the JR method based on the boiling point of peroxy acetyl nitrate reported by Bruckmann and Willner (1983). Bruckmann and Willner (1983) do not make explicit how this boiling point of $379.15 \mathrm{~K}$ was determined. As they evaluated the vapor pressure curve only up to $291.15 \mathrm{~K}$, the reported boiling point of peroxy acetyl nitrate is probably obtained by extrapolation of their $p^{0}(T)$ correlation over almost $90 \mathrm{~K}$. Therefore we use instead the $p^{0}(T)$ correlation provided by Kacmarek (1978) to obtain the extrapolated boiling point of peroxy acetyl nitrate (Table 2). With this boiling point, the group contribution for peroxy acyl nitrates is determined (Table 3). Kacmarek (1978) provides $T, p^{0}$ data up to $330.15 \mathrm{~K}$, although the highest temperature point is probably an outlier not used in their correlation. Discarding this point results in a - still significant - extrapolation range of about $60 \mathrm{~K}$.

As no experimental boiling points are available for hydroperoxides, Camredon and Aumont (2006) assumed that the group $-\mathrm{OOH}$ could be subdivided into the existing JR groups $-\mathrm{O}-$ and $-\mathrm{OH}$. Instead, we use the $p^{0}(T)$ correlations provided by Egerton et al. (1951) to obtain the extrapolated boiling points of three hydroperoxides and three peracids. For five out of six of them the extrapolation range is less than $20 \mathrm{~K}$ and hence the extrapolated boiling point should be a good estimate, provided the underlying data is of good quality. These boiling points are then used to derive the group contribution for the hydroperoxide group and peracid 
Table 2. Boiling points used for the derivation of new group contributions, together with the range of extrapolation $\Delta T_{\text {extr. }}$ to obtain these boiling points, when applicable.

\begin{tabular}{lcc}
\hline compound & $T_{b} / \mathrm{K}$ & $\Delta T_{\text {extr. }} / \mathrm{K}$ \\
\hline dimethyl peroxide $^{\mathrm{a}}$ & 287.15 & 0.5 \\
diethyl peroxide $^{\mathrm{a}}$ & 335.65 & $\mathrm{~N} / \mathrm{A}$ \\
di-t-butyl peroxide $^{\mathrm{a}}$ & 382.15 & $\mathrm{~N} / \mathrm{A}$ \\
ethyl methyl peroxide $^{\mathrm{b}}$ & 312.15 & $\mathrm{~N} / \mathrm{A}$ \\
isopropyl methyl peroxide $^{\mathrm{b}}$ & 326.65 & $\mathrm{~N} / \mathrm{A}$ \\
t-pentyl t-butyl peroxide $^{\mathrm{b}}$ & 399.15 & $\mathrm{~N} / \mathrm{A}$ \\
methyl hydroperoxide $^{\mathrm{c}}$ & 358.60 & 45.5 \\
ethyl hydroperoxide $^{\mathrm{c}}$ & 374.25 & 11.0 \\
t-butyl hydroperoxide $^{\mathrm{c}}$ & 404.65 & 11.5 \\
acetic peracid $^{\mathrm{c}}$ & 383.24 & $\approx 0^{\mathrm{d}}$ \\
propanoic peracid $^{\mathrm{c}}$ & 392.88 & $\approx 0^{\mathrm{d}}$ \\
butanoic peracid $^{\mathrm{c}}$ & 399.38 & 6. \\
peroxy acetyl nitrate $^{\mathrm{e}}$ & 377.07 & 61.1 \\
\hline
\end{tabular}

${ }^{a}$ From Sanchez and Myers (2000). For dimethyl peroxide, the boiling point was slightly below $1 \mathrm{~atm}$, therefore we assumed a $0.5 \mathrm{~K}$ higher $T_{b}$.

b From Balaban et al. (1992).

${ }^{\mathrm{c}}$ From the $p^{0}(T)$ correlations of Egerton et al. (1951).

$\mathrm{d}$ The boiling points are at the edge of the reported temperature interval. However, Egerton et al. (1951) do not refer to them as directly determined boiling points.

e From the $p^{0}(T)$ correlation of Kacmarek (1978). The highest temperature data point at $330.15 \mathrm{~K}$ is probably an outlier, seemingly not used by Kacmarek (1978) for the derivation of the vapor pressure function of peroxy acetyl nitrate. Therefore the extrapolation range is taken from the second-highest temperature data point $315.95 \mathrm{~K}$.

group, by minimizing

$\sum_{i}\left(T_{b, X, i}-T_{b, \exp , i}\right)^{2}$

with $X$ the method considered (in this case JR) and $T_{b \text {,exp, } i}$ a boiling point based on experimental data (possibly extrapolated) (Table 3). The peroxide group contribution finally, is based on six boiling points from Sanchez and Myers (2000) and Balaban et al. (1992) evaluated at, or very close to, atmospheric pressure.

Also reported in Table 3 are the mean absolute deviations between modelled and experimental (possibly extrapolated) boiling points, given as

$\sigma_{T_{b}}=1 / N \sum_{i=1}^{N}\left|T_{b, X, i}-T_{b, \exp , i}\right|$

\subsection{Boiling point method of Nannoolal et al. (2004), and its extension}

This is a group contribution method that also takes into account interactions between functional groups.

$T_{b, \mathrm{~N}}=\frac{\sum_{k} v_{k} \Delta T_{b, k}+\mathrm{GI}}{n^{0.6583}+1.6868}+84.3395$

$\mathrm{GI}=\frac{1}{n} \sum_{i=1}^{m} \sum_{j=1}^{m} \frac{C_{i-j}}{m-1}$, with $\begin{aligned} & n \text { number of non }-\mathrm{H} \text { atoms } \\ & m \text { number of interacting groups }\end{aligned}$

The nonlinear behaviour (through the term $n^{0.6583}$ ) describes more closely experimental behaviour as opposed to the JR method. $\Delta T_{b, k}$ includes both first and second order groups. GI describes the interaction between groups. It includes a large amount of functional groups, is therefore applicable to a wide range of organic molecules, and is based on the renowned Dortmund Data Bank (www.ddbst.com). However no parameters are available for the hydroperoxide, the peracid and peroxy acyl nitrate group. They are obtained in the same way as for the JR method (Table 3). As the boiling points upon which are based were estimated, the group contribution values are presumably of lower quality. No group interaction parameters $C_{i-j}$ can be derived for these groups because of lack of data.

\subsection{Vapor pressure method of Capouet and Müller (2006)}

This is a simple group contribution method directly fitted to experimental vapor pressures, given by the formula

$\log _{10} p_{\mathrm{CM}}^{0}=\log _{10} p_{h c}^{0}-\sum_{k} v_{k} \tau_{k}$

$\tau_{k}=A_{k}-B_{k}(T-298 \mathrm{~K})$

$p_{h c}^{0}$ is the vapor pressure of the hydrocarbon parent compound of the molecule under consideration, i.e. the molecule with the same carbon skeleton but with the functional groups replaced by the appropriate number of hydrogen atoms, and $k$ runs over the functional groups. This hydrocarbon vapor pressure is provided by experimental data or estimated by some other method, as there exist several reliable ways to estimate the vapor pressure of hydrocarbons. For the fitting, the large majority of $p_{h c}^{0}$ was provided by experimental values, while for the use in modeling, the method of Marrero and Gani (2001) was used to provide boiling point, critical temperature and critical pressure, which were then converted to $p_{h c}^{0}$ by the corresponding states method of Ambrose and Walton (1989). This last approach was also chosen in this work. Note that the method lumps acids and peracids, but distinguishes between primary, secondary and tertiary alcohols and nitrates. A shortcoming of the CM method is its limited range of applicability with respect to molecule types, as it was devised to handle oxidation products of terpenes. Furthermore, it is based on a relatively limited basis set, and it includes only a crude temperature dependence. 
Table 3. Group contribution values for the methods of Joback and Reid (1987), Nannoolal et al. (2004), Nannoolal et al. (2008) and Moller et al. (2008), for groups not covered in these papers. Boiling points from Table 2 were used. The mean absolute deviations of the modelled vs. the experimental or extrapolated $T_{b}$, and the modelled vs. the experimental $\log _{10}\left(p^{0}\right)$ are also given.

\begin{tabular}{|c|c|c|c|c|c|c|c|c|}
\hline \multirow{2}{*}{$\begin{array}{l}\text { Method extended } \\
\text { group }\end{array}$} & \multicolumn{2}{|c|}{ Joback and Reid (1987) } & \multicolumn{2}{|c|}{ Nannoolal et al. (2004) } & \multicolumn{2}{|c|}{ Nannoolal et al. (2008) } & \multicolumn{2}{|c|}{ Moller et al. (2008) } \\
\hline & $\Delta T_{b, k}$ & $\sigma_{T_{b}}$ & $\Delta T_{b, k}$ & $\sigma_{T_{b}}$ & $d B \times 10^{3}$ & $\sigma_{\log _{10} p^{0}}$ & $d B$ & $\sigma_{\log _{10} p^{0}}$ \\
\hline$-\mathrm{OO}-$ & 28.7 & 16.1 & \multicolumn{6}{|c|}{ Group already present in original method. } \\
\hline$-\mathrm{OOH}$ & 127.96 & 7.0 & 774.75 & 1.3 & $888.42^{\mathrm{a}}$ & 0.05 & $1.7817^{\mathrm{a}}$ & 0.05 \\
\hline$-\mathrm{C}(=\mathrm{O}) \mathrm{OOH}$ & 147.17 & 10.2 & 1110.64 & 12.3 & $926.02^{\mathrm{b}}$ & 0.03 & $1.7924^{\mathrm{b}}$ & 0.03 \\
\hline$-\mathrm{C}(=\mathrm{O}) \mathrm{OONO}_{2}$ & 155.29 & l & 1467.2 & I & $519.03^{\mathrm{c}}$ & 0.008 & $0.8508^{\mathrm{c}}$ & 0.009 \\
\hline
\end{tabular}

${ }^{a}$ Based on $p^{0}(T)$ correlations of methyl, ethyl and t-butyl hydroperoxide (Egerton et al., 1951).

${ }^{\mathrm{b}}$ Idem for acetic, propanoic and butanoic peracid.

${ }^{c}$ Based on the $T, p^{0}$ data points of peroxy acetyl nitrate (Kacmarek, 1978), excluding the highest temperature point.

Table 4. Ether, peroxide and ester group contributions as an extension of Capouet and Müller (2006).

\begin{tabular}{lll}
\hline Group & $A$ & $B$ \\
\hline$-\mathrm{O}-{ }^{\mathrm{a}}$ & 0.4107 & 0.00594 \\
$-\mathrm{OO}-\mathrm{b}$ & 0.18 & 0.0027 \\
$-\mathrm{C}(=\mathrm{O}) \mathrm{O}-^{\mathrm{c}}$ & 0.9171 & 0.00451 \\
\hline
\end{tabular}

a Based on data from ESDU (1995) of ethyl propyl, methyl pentyl, dibutyl and dipentyl ether.

$\mathrm{b}$ Based on data from Egerton et al. (1951) of di-t-butyl peroxide.

c Based on data from ESDU (2001) of diethyl succinate, diethyl suberate and diethyl sebacate.

Note that the definition of the hydrocarbon parent for ethers, esters and peroxides (which all have one or more oxygens within the hydrocarbon skeleton) was not considered by Capouet and Müller (2006), as these molecules did not play a role in the version of their chemical model at that time. An update of the BOREAM model (Capouet et al., 2008) based on the new chemistry provided by Vereecken et al. (2007), led to the inclusion of several compounds containing ether, ester and peroxide functionalities. The parent hydrocarbon is then defined as if the two carbon atoms on the opposite sides of the in-chain oxygen atom(s) are directly attached to each other. In the estimation of $p_{h c}^{0}$, second order effects from the method of Marrero and Gani (2001) due to for example neighbouring methyl groups on these two carbon atoms were neglected, as they would obviously also not occur in the child molecule. The group contributions were fitted to a few simple molecules, and the results are shown in Table 4.

\subsection{SIMPOL (Pankow and Asher, 2008)}

Like the previous model, SIMPOL assumes the additivity of functional group contributions to the logarithm of the vapor pressure. The vapor pressure is given by the formula

$\log _{10} \frac{p_{\mathrm{SI}}^{0}}{1 \mathrm{~atm}}=\sum_{k} v_{k} b_{k}(T)$

where the sum includes a contribution which is constant for all molecules $(k=0)$, a contribution proportional to the number of carbon atoms $(k=1)$, as well as first and second order groups $(k>1)$. An important difference with the method of Capouet and Müller (2006) is that there is no distinction between primary, secondary and tertiary alcohols and nitrates.

\subsection{SPARC}

The on-line method SPARC (Carreira et al., 1994) calculates a set of molecular descriptors (molecular polarizability, molecular volume, microscopic dipole, hydrogen bond) from atomic fragments. From these, several other pure component properties (vapor pressure, boiling point, ... Hilal et al., 2003) and mixture properties (activity coefficient, Henry's law constant,... Hilal et al., 2004) can be calculated. The vapor pressure is calculated with a detailed solute-solute interaction model. We did not implement the code of SPARC, as we don't have access to its current version, but we have calculated the vapor pressure of all condensable explicit species occurring in BOREAM on-line with SPARC, version 4.2 (http://ibmlc2.chem.uga.edu/sparc/).

\subsection{Method of Myrdal and Yalkowsky (1997)}

The vapor pressure of a liquid is estimated through the relatively simple formula

$\log _{10}\left(\frac{p_{\mathrm{MY}}^{0}}{1 \mathrm{~atm}}\right)=-\frac{\left[86.0+0.4 \tau+1421 \frac{\sqrt{\mathrm{HBG}}}{M}\right]\left(T_{b}-T\right)}{19.1 T}$ 
$+\frac{-90.0-2.1 \tau}{19.1}\left(\frac{T_{b}-T}{T}-\ln \frac{T_{b}}{T}\right)$

with $T_{b}$ the boiling point, $M$ the molecular mass, $\tau$ the number of torsional bonds and \# HBG the number of hydrogen bonding groups. This last term takes into account the non-additive nature of hydrogen bonding groups. The hydrogen bonding amines were treated differently by Myrdal and Yalkowsky (1997), but they do not occur in the chemical oxidation mechanism of $\alpha$-pinene. Myrdal and Yalkowsky (1997) classified carboxylic acids and alcohols as hydrogen bonding groups, Camredon and Aumont (2006) categorized also hydroperoxides as hydrogen bonding, and in this work we do the same for peracids. The hydrogen bonding nature of hydroperoxides and peracids is clear given their low vapor pressure. In the study of Barley and McFiggans (2010), it was found that this method tended to overpredict vapor pressures of lower-volatility compounds.

\subsection{Vapor pressure method of Nannoolal et al. (2008),} and its extension

This is a very recent group contribution method that needs a boiling point as input:

$$
\begin{aligned}
& \log _{10}\left(\frac{p_{\mathrm{N}}^{0}}{1 \mathrm{~atm}}\right)= \\
& {\left[4.1012+\left(\sum_{k} v_{k} C_{k}+\mathrm{GI}-0.176055\right)\right] \frac{T-T_{b}}{T-\frac{1}{8} T_{b}}} \\
& \mathrm{GI}=\frac{1}{n} \sum_{i=1}^{m} \sum_{j=1}^{m} \frac{C_{i-j}}{m-1}, \text { with }{ }_{m}^{n} \text { numberofnon }- \text { Hatoms } \\
& \text { numberofinteractinggroups }
\end{aligned}
$$

The groups $k$ defined are (nearly) identical to those of the boiling point estimation method of Nannoolal et al. (2004), hence has about the same wide range of applicability and is also based on the Dortmund Data Bank. Also this method takes into account group-group interaction. A large number of parameters is needed for the group-group interaction, and in some cases they are constrained by vapor pressure data of only 1 or 2 compounds. Since the double summation in GI is divided by both $n$ and $m-1$, GI becomes less important with increasing number of interacting groups compared to $\sum_{k} v_{k} C_{k}$. In itself, this looks somewhat illogical; why would the group interaction become negligible for highly polyfunctional molecules? In practice, this means that for highly polyfunctional molecules the method of Nannoolal et al. (2008) becomes closer to a simple group-contribution method.

As for the boiling point method (Nannoolal et al., 2004), no groups are available for hydroperoxides, peracids and peroxy acyl nitrates. There are, however, vapor pressure data available for all these compounds (Egerton et al., 1951; Kacmarek, 1978; Bruckmann and Willner, 1983). Together with their extrapolated boiling points (see above), this allows to obtain group contribution values for the vapor pressure methods (see Table 3 ). This is done by minimizing

$$
\sum_{i} \sum_{j}\left(\log _{10}\left(\frac{p_{X, i}^{0}\left(T_{j}\right)}{p_{\exp \left(T_{j}\right), i}^{0}}\right)\right)^{2}
$$

For the hydroperoxides and peracids $p_{\exp , i}^{0}$ is a $p(T)$ correlation (Egerton et al., 1951) and $T_{j}$ runs over the temperature interval where this correlation is valid, with a step of $1 \mathrm{~K}$. For peroxy acetyl nitrate, $p_{\exp , i}^{0}\left(T_{j}\right)$ runs over the data points reported by Kacmarek (1978), except for the highest temperature point, which is considered an outlier. Also given are the mean absolute deviations between modelled and experimental $\log _{10} p^{0}$.

$\sigma_{\log _{10} p^{0}}=\sum_{i} \sum_{j}\left|\log _{10} \frac{p_{X, i}^{0}\left(T_{j}\right)}{p_{\exp \left(T_{j}\right), i}^{0}}\right|$

No group interaction parameters $C_{i-j}$ were obtained for these groups as data is lacking. However, group-interaction can be especially important for the hydrogen-bonding hydroperoxide and peracid groups. One could of course assume group-interaction parameters from another group resembling these groups, e.g. taking over the GI alcohols parameters for hydroperoxides, and the GI acid parameters for peracids. But the magnitude of the group-interaction parameters depends on the magnitude of the group contribution of the functional group, and these are different for alcohol and hydroperoxide, and for acid and peracid groups. Hence simply taking over these GI values is probably not justified. We will take this approach only as a sensitivity test.

\subsection{Vapor pressure method of Moller et al. (2008), and its extension}

This method is a successor to that of Nannoolal et al. (2008), and has many identical or similar groups.

$$
\begin{aligned}
& \ln \left(\frac{p_{\mathrm{M}}^{0}}{1 \mathrm{~atm}}\right)=\left(9.42208+\sum_{k} v_{k} d B_{k}+n_{a} \sum_{l} v_{l} d B_{l}+\mathrm{GI}\right)(12) \\
& \times \frac{T-T_{b}}{T-\left(\frac{T_{b}^{1.485}}{135}-2.65\right)}+D^{\prime} \ln \frac{T}{T_{b}} \\
& D^{\prime}=D+\frac{1}{n_{a}} \sum v_{i} d E_{i}, \text { correction term for acids and alcohols } \\
& \mathrm{GI}=\frac{1}{2} \sum_{i=1}^{m} \sum_{j=1}^{m} C_{i-j}, \text { with } m \text { number of interacting groups }
\end{aligned}
$$

with $n_{a}$ the number of nonhydrogen atoms. Differences with Nannoolal et al. (2008) include: some of the group contributions are molecule size dependent (through the factor $n_{a}$ ); a correction term is included for acids and alcohols $\left(D^{\prime}\right)$; and the scaling of the group interaction term GI. As opposed to the method of Nannoolal et al. (2008), the 
Table 5. Comparison of experimental vapor pressure data points of hydroperoxides and a peracid, from Sanchez and Myers (2000), with calculations by the extended MY-JR and the Mol-Nan methods. The extended Nan-Nan and MY-Nan methods (not shown) have $\Delta_{\text {exp }}^{X}=0.07$, $\sigma_{\exp }^{X}=0.30$ and $\Delta_{\exp }^{X}=0.09, \sigma_{\exp }^{X}=0.32$, respectively.

\begin{tabular}{|c|c|c|c|c|c|c|}
\hline & $\frac{T}{\mathrm{~K}}$ & $\frac{p_{\exp }^{0}}{\text { Torr }}$ & $\frac{p_{\mathrm{MY}}^{0}\left(T_{b, \mathrm{JR}}\right)}{\text { Torr }}$ & $\log _{10} \frac{p_{\mathrm{MY}}^{0}\left(T_{b, \mathrm{JR}}\right)}{p_{\exp }^{0}}$ & $\frac{p_{\text {Mol }}^{0}\left(T_{b, \text { Nan }}\right)}{\text { Torr }}$ & $\log _{10} \frac{p_{\mathrm{Mol}}^{0}\left(T_{b, \mathrm{Nan}}\right)}{p_{\exp }^{0}}$ \\
\hline isopropyl hydroperoxide & 311.40 & 20.03 & 18.14 & -0.04 & 26.00 & 0.11 \\
\hline n-butyl hydroperoxide & 428.03 & 8.03 & 7.39 & -0.04 & 4.71 & -0.23 \\
\hline sec-butyl hydroperoxide & 415.45 & 11.03 & 8.01 & -0.14 & 9.28 & -0.07 \\
\hline t-pentyl hydroperoxide & 427.23 & 6.98 & 2.04 & -0.53 & 3.66 & -0.28 \\
\hline cyclohexyl hydroperoxide & 480.05 & 1.20 & 1.24 & 0.01 & 1.22 & 0.006 \\
\hline n-heptyl hydroperoxide & 491.44 & 0.06 & 0.30 & 0.71 & 0.17 & 0.45 \\
\hline 3-ethyl 3-pentyl hydroperoxide & 470.50 & 17.03 & 3.08 & -0.74 & 4.66 & -0.56 \\
\hline methyl cyclohexyl hydroperoxide & 488.80 & 0.03 & 0.10 & 0.54 & 0.24 & 0.90 \\
\hline 1,1,3,3-tetramethyl butyl hydroperoxide & 471.70 & 0.90 & 0.20 & -0.66 & 0.82 & -0.04 \\
\hline hexanoic peracid & 462.81 & 0.50 & 1.16 & 0.36 & 0.86 & 0.23 \\
\hline$\Delta_{\exp }^{X}$ & & & & -0.05 & & 0.05 \\
\hline$\sigma_{\exp }^{X}$ & & & & 0.36 & & 0.29 \\
\hline
\end{tabular}

group-interaction term can become dominant compared to $\sum_{k} v_{k} d B_{k}$ for molecules with many interacting groups, and this can have a profound effect on the vapor pressure, as we will show below. In the same way as for the Nannoolal et al. (2008) method we derived group contributions for hydroperoxides, peracids and peroxy acyl nitrates (Table 3 ), while no GI values could be obtained. In the recent assessment of Barley and McFiggans (2010), both this method and the method of Nannoolal et al. (2008), in combination with the boiling point method of Nannoolal et al. (2004), came out as the preferred methods.

\section{Cross-validation of methods extended in this work}

Sanchez and Myers (2000) provide reduced pressure boiling points of hydroperoxides and peracids. These were used to test the hydroperoxide and peracid group extensions made in this work for some methods (Table 5). Only nonaromatic (as we did not implement aromatic groups) and monofunctional molecules were considered. The mean deviation - or systematic difference $-\Delta_{Y}^{X}$ and mean absolute deviation $\sigma_{Y}^{X}$ are given by

$$
\begin{aligned}
& \Delta_{Y}^{X}=\frac{1}{N} \sum_{i} \log _{10} \frac{p_{X, i}^{0}}{p_{Y, i}^{0}} \\
& \sigma_{Y}^{X}=\frac{1}{N} \sum_{i}\left|\log _{10} \frac{p_{X, i}^{0}}{p_{Y, i}^{0}}\right|
\end{aligned}
$$

with $X$ a vapor pressure model and $Y$ another vapor pressure model or (as in this case) experiment. In this last case $\Delta_{\exp }^{X}$ is the bias of model $X$. For all methods tested, the bias was low $(-0.05-0.09)$, while the mean absolute deviation was around 0.3 . Note that the peroxy acyl nitrate group extension could not be tested, as no vapor pressure data are available for other peroxy acyl nitrates than peroxy acetyl nitrate.

\section{Application of vapor pressure methods to BOREAM- predicted $\alpha$-pinene degradation products}

We applied the different vapor pressure methods to the condensable, explicit ${ }^{1} \alpha$-pinene degradation products ( 254 in total) as predicted by BOREAM. These molecules contain carbonyl, hydroxyl, acid, nitrate, peracid, hydroperoxide, peroxy acyl nitrates, and to a smaller extent, ether, ester and peroxide functionalities. Note that as we had to extend some methods to treat certain functional groups (hydroperoxides, peracids, peroxy acyl nitrates), and that these extensions are based on the same small set of vapor pressure data, these methods will have similar contributions to the vapor pressure for these functional groups.

\subsection{CM method: dependence on parent hydrocarbon vapor pressure estimation method}

The CM method starts from the vapor pressure of the parent hydrocarbon, and the vapor pressure is then lowered by considering the functional groups. In the basis set for fitting of the method, the vapor pressure of the parent hydrocarbon is known in the large majority of cases. However, this is not the case for most condensable molecules in BOREAM, and $\log _{10} p_{h c}^{0}$ in Eq. (7) has to be estimated by some method. The choice of this method will have an impact on the end result $\log _{10} p^{0}$.

Generally, we use the method of Marrero and Gani (2001) to predict boiling point, critical temperature and critical pressure. The hydrocarbon vapor pressure is then calculated from these properties by the corresponding states method of Ambrose and Walton (1989) (Eq. (8) of their paper), with the

\footnotetext{
1 "Explicit" meaning having a definite chemical structure, as there are also lumped species in BOREAM with more limited chemical information.
} 

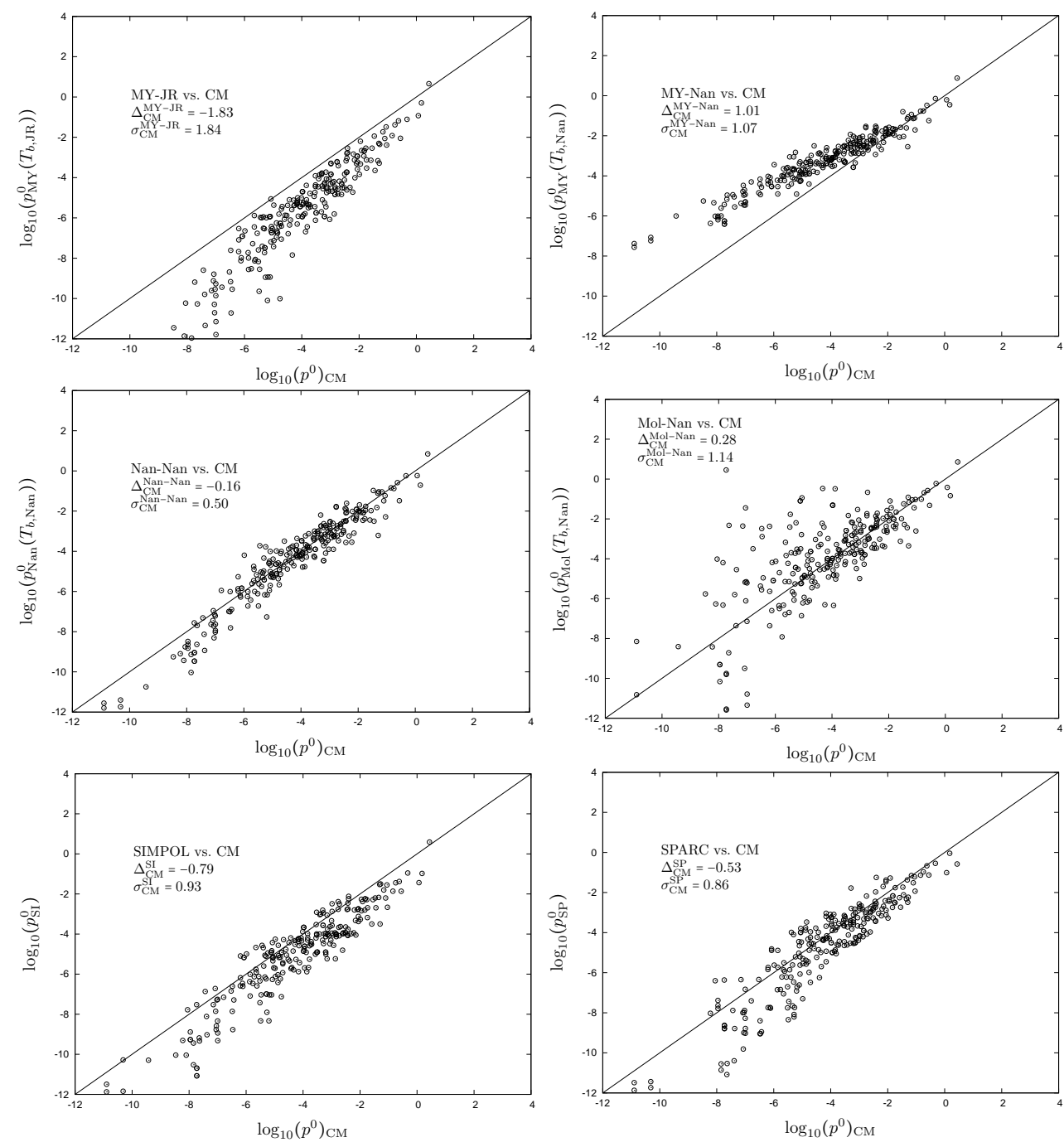

Fig. 1. Logarithm of vapor pressure estimations at $298 \mathrm{~K}$ of all explicit condensable molecules in BOREAM vs. the CM method. The black line is the 1:1 diagonal. Given are also the mean deviation $\Delta$ and the mean absolute deviation with the CM method.

acentric factor estimated with Eq. (2-3.3) of Poling et al. (2001). Note that this method fails when the temperature of interest is above the critical temperature of the parent hydrocarbon. In practice, this only arises for molecules with only 1 or 2 carbon atoms and hence are of no concern for the condensable molecules in BOREAM. To investigate the influence of method choice on $\log _{10} p_{h c}^{0}$, we used as an alternative the combined methods of Nannoolal et al. (2004) and Nannoolal et al. (2008). At $298 \mathrm{~K}$, we find almost no mean deviation (Eq. 13) between both methods, and the mean absolute deviation is only 0.13 (Eq. 14). When using SIMPOL (Pankow and Asher, 2008) to calculate the parent hydrocarbon part, the difference is larger: SIMPOL predicts on average a $0.23 \operatorname{lower}_{\log _{10}} p_{h c}^{0}$, with a mean absolute deviation of 0.25 . SIMPOL calculates the hydrocarbon part of the vapor pressure in a rather rudimentary way. Nonetheless, even this difference in $\log _{10} p_{h c}^{0}$ is small compared to the variations in $\log _{10} p^{0}$ of the functionalized molecules between the different vapor pressure estimation methods discussed below. We conclude that the choice of method for calculation of $\log _{10} p_{h c}^{0}$ is relatively unimportant.

\subsection{Comparing vapor pressure estimations of explicit condensing molecules in BOREAM}

In this comparison, the method of Capouet and Müller (2006) is taken as the reference method, as it was used for our previous simulations with BOREAM. In Fig. 1 the logarithm of vapor pressure estimated at $298 \mathrm{~K}$ by each method is plotted against the corresponding values estimated with the $\mathrm{CM}$ method. In addition, the mean deviation $\Delta_{\mathrm{CM}}^{Y}$ and mean absolute deviation $\sigma_{\mathrm{CM}}^{Y}$ (see Eqs. 13 and 14) are also given. 


\subsubsection{MY-JR}

It can be seen that MY-JR predicts considerably lower vapor pressures as compared with the CM method for practically all explicit condensable molecules in BOREAM (called BOREAM-molecule hereafter), and this deviation is larger for the lower vapor pressures. It is a known shortcoming of the JR boiling point estimation method to overpredict high boiling points because of the linearity assumption (Eq. (2), see e.g. Stein and Brown, 1994), which leads to a severe underprediction of the low vapor pressures, almost irrespective of the exact vapor pressure estimation method used (Barley and McFiggans, 2010). Therefore, we can only advise not to use the JR method for SOA formation applications.

\subsubsection{MY-Nan}

As opposed to JR, the Nannoolal boiling point method is carefully calibrated to reproduce the observed evolution of boiling point with molecule size. The MY-Nan method agrees with $\mathrm{CM}$ for the highest vapor pressures, but starts to deviate at $\log _{10} \frac{p_{\mathrm{CM}}^{0}}{\text { Torr }}=-2$, and overpredicts the vapor pressure by about 2 orders of magnitude at $\log _{10} \frac{p_{\mathrm{CM}}^{0}}{\text { Torr }}=-9$. From the current study alone it cannot be concluded which method is closer to the true vapor pressure, but we note that an overestimation of MY-Nan at lower vapor pressures (as opposed to both experiment and Nan-Nan) was noted by Barley and McFiggans (2010).

The MY method starts from the Clausius-Clapeyron equation assuming a constant difference of heat capacity:

$$
R \ln \frac{p^{0}}{\mathrm{~atm}} \approx-\Delta S_{b}\left(\frac{T_{b}-T}{T}\right)+\Delta C_{p}\left(\frac{T_{b}-T}{T}-\ln \frac{T_{b}}{T}\right)
$$

It can be anticipated that the assumption of constant $\Delta C_{p}$ will break down from a certain difference $T_{b}-T$ on. Methods based on the Antoine equation (Nannoolal et al., 2008; Moller et al., 2008, see below) have probably a wider range of applicability. However, more investigation is needed to clarify which method is closer to the true experimental vapor pressure.

\subsubsection{Nan-Nan}

When combining both the Nannoolal boiling point and vapor pressure method (Nan-Nan) a remarkably good agreement with $\mathrm{CM}$ is obtained. This is somewhat surprising as both $p_{\mathrm{N}}, T_{b, \mathrm{~N}}$ are very detailed methods and based on the large and recommended Dortmund Data Bank, while the CM method is a relatively simple method based on a limited set of vapor pressures.

As explained in Sect. 2.7, the group-group interactions in the method of Nannoolal et al. (2008) become unimportant for highly polyfunctional molecules. We checked this by setting GI=0 in the method of Nannoolal et al. (2008) and comparing with the original method: the systematic difference in $\log _{10}(p)$ is only 0.12 , and the mean absolute difference only 0.14 . This is a relatively small difference, which arguably does not justify the large number of parameters, often constrained by only a few measurements, needed to calculate GI. We note in this respect that Barley and McFiggans (2010) devised a simplified version of the method of Nannoolal et al. (2008), with fewer parameters and without group interactions, and found that this method performed almost as well as the original method when tested against their experimental vapor pressures.

\subsubsection{Mol-Nan}

The Moller method is a close successor to the Nannoolal vapor pressure method. Although a good agreement is obtained with both CM and Nan-Nan for a large number of SOA products (Fig. 1) there are also many outliers, with both large under- and overestimations in comparison to CM. Note that these large outliers disappear when GI is set to zero in Eq. (13). Striking examples of vapor pressure overestimation include the following cases. The vapor pressure of the BOREAM-molecule $\mathrm{CHOH}\left(\mathrm{C}\left(\mathrm{CH}_{3}\right)_{2} \mathrm{OH}\right) \mathrm{CH}_{2} \mathrm{COCOCH} 3$, with 7 carbon atoms and four functional groups, is predicted to be 0.33 Torr at $298 \mathrm{~K}$, about the same vapor pressure as that of the small molecule 1-heptanol (experimental vapor pressure: 0.22 Torr), with only 1 functional group. $\mathrm{HOCH}_{2}(\mathrm{CHOH})_{8} \mathrm{CH}_{2} \mathrm{OH}$ has a predicted vapor pressure of $2 \times 10^{-3}$ Torr at $298 \mathrm{~K}$, about $1 / 3$ of the experimental vapor pressure of 1-decanol $\left(7 \times 10^{-3}\right.$ Torr $)$, while the molecule $\mathrm{HOCH}_{2}(\mathrm{COCHOH})_{4} \mathrm{CHO}$, is calculated to have a negative enthalpy of vaporization, and as a consequence the calculated vapor pressure becomes unrealistically large at $298 \mathrm{~K}\left(>1.7 \times 10^{34}\right.$ Torr) (these last two examples are not BOREAM-molecules, but are included to show the limiting behaviour). In the latter case, the overestimation is caused by the large negative, and badly constrained (only 2 measurements) alcohol-keto group interaction term. However, the general cause of the wrong behaviour can be attributed to the way group interactions are counted (see Eq. 13) in the Moller method, where the GI term dominates the group contribution terms in presence of many functional groups. Currently, the method has been reworked by Moller and coworkers based on this analysis, and a correction will be published shortly (B. Moller, personal communication, 2010; see also the discussion phase of this work).

We mention finally that this anomaly is unrelated to the one mentioned by Barley et al. (2009), where a steep increase in vapor pressure was observed between the C5 and C6 diacids. Our implemented version following the publication of Moller et al. (2008) suffers from exactly the same problem. This error is also corrected in the reworked version. As the BOREAM-molecules tested here do not include diacids with less than 10 atoms, it is unimportant for the present intercomparison exercise. 
Table 6. $\log _{10}\left(\frac{p^{0}}{\text { Torr }}\right)$ as estimated by the different vapor pressure methods to some experimentally identified $\alpha$-pinene oxidation products.

\begin{tabular}{lrrrrrrr}
\hline & CM & MY-JR & MY-Nan & Nan-Nan & Mol-Nan & SIMPOL & SPARC \\
\hline pinonaldehyde & -1.17 & -1.73 & -0.93 & -1.04 & -1.04 & -1.80 & -1.15 \\
pinonic acid & -3.52 & -4.44 & -2.78 & -3.49 & -4.15 & -4.0 & -4.55 \\
pinic acid $_{\text {MBTCA }^{\mathrm{a}}}$ & -5.34 & -6.51 & -4.08 & -5.29 & -5.78 & -6.14 & -7.45 \\
terpenylic acid $^{\mathrm{b}}$ & -8.26 & -10.2 & -6.38 & -9.17 & -6.73 & -9.21 & -7.73 \\
2-hydroxy terpenylic acid $^{\mathrm{b}}$ & -2.53 & -3.54 & -3.90 & -4.55 & -5.69 & -3.37 & -5.02 \\
diaterpenylic acid acetate $^{\mathrm{b}}$ & -6.88 & -6.10 & -5.21 & -6.84 & -8.76 & -5.55 & -6.52 \\
\hline
\end{tabular}

a 3-methyl-1,2,3-butane-tricarboxylic acid was characterized by Szmigielski et al. (2007).

$\mathrm{b}$ These molecules were characterized by Claeys et al. (2009).

In any case, the fact that this method came out as the best from the assessment of Barley and McFiggans (2010), implies that it can be applied to molecules with a limited number of functional groups.

\subsubsection{SIMPOL and SPARC}

SIMPOL predicts lower vapor pressures compared to the CM method for the large majority of compounds. This is for the largest part due to the higher vapor pressures CM predicts for tertiary alcohols, while SIMPOL makes no distinction between primary, secondary and tertiairy alcohols. A second, less important, reason is the lower vapor pressure SIMPOL predicts for the carbon skeleton.

SPARC predicts on average lower vapor pressures compared to the CM method, but there is considerable overlap between both methods.

\subsubsection{Sensitivity test: group interaction parameters for hydroperoxides and peracids in MY-Nan, Nan- Nan and Mol-Nan}

As explained above, no group interaction parameters could be obtained for hydroperoxides, peracids and peroxy acyl nitrates in the methods of Nannoolal et al. (2004, 2008); Moller et al. (2008). However, especially for the hydrogenbonding hydroperoxides and peracids they could be important. Therefore, we recalculated the vapor pressures of the BOREAM molecules with the methods MY-Nan, Nan-Nan and Mol-Nan, but where hydroperoxides are counted as alcohols and peracids as acids in the calculation of the GI term of Nannoolal et al. (2004, 2008); Moller et al. (2008). These last calculations are refered to as the analogy test, while the original calculations (with zero group interaction parameters for $\mathrm{OOH}$ and $\mathrm{C}(=\mathrm{O}) \mathrm{OOH})$ are the base case. Over the whole set of molecules, most of which do not contain the $\mathrm{OOH}$ or $\mathrm{C}(=\mathrm{O}) \mathrm{OOH}$ group, the mean deviation and mean absolute deviation of the analogy test compared to the base case for MY-Nan and Nan-Nan $\log _{10} p^{0}$ is negligible (0.02 or smaller), while for Mol-Nan an on average 0.25 lower $\log _{10} p^{0}$ is predicted. Hence the basic conclusions of the comparisons above are not changed. Considering the mean deviation and mean absolute deviation only over the compounds with $\mathrm{OOH}$ and/or $\mathrm{C}(=\mathrm{O}) \mathrm{OOH}$ groups, $\log _{10} p^{0}$ from the analogy test are still only marginally different from the base case for MY-Nan and Nan-Nan (less than 0.1), while for Mol-Nan, vapor pressures are about an order of magnitude lower with the analogy test calculations compared to the base case. Clearly, the agressive scaling of the GI parameter of the method of Moller et al. (2008) is responsible for this high sensitivity.

\section{Application of vapor pressure methods to experimentally found $\alpha$-pinene oxidation products}

In Table 6 we apply the different vapor pressure methods to some experimentally characterized $\alpha$-pinene oxidation products. Apart from the well-known compounds pinonaldehyde, pinic acid and pinonic acid, these include more recent identified products from Szmigielski et al. (2007); Claeys et al. (2009). In general, also for these compounds the MY-JR yields the lowest, and the MY-Nan the highest vapor pressure. For compounds containing an ester functionality, the CM method predicts a relatively high vapor pressure. While the methods are reasonably in agreement for the semi-volatile molecules pinonaldehyde and pinonic acid, the disagreement becomes very substantial for the low-volatility molecules.

\section{Conclusions}

As mentioned by Barley et al. (2009), vapor pressure equations using critical data are probably less appropriate for atmospheric modelling, due to the very large difference between the critical temperature with the temperature of interest. This applies also to a lesser extent to vapor pressure equations using boiling points; the boiling point is typically $300 \mathrm{~K}$ above the temperature of interest. The danger 
of bad extrapolation from this boiling point is exemplified by the large differences between the methods of Myrdal and Yalkowsky (1997) and Nannoolal et al. (2008), using the same boiling point estimation method. Another drawback is that for some types of compounds (peroxy acyl nitrates, hydroperoxides and peracids) no boiling points are available as they decompose before the boiling point is reached; in this work we had to extend the methods of Joback and Reid (1987); Nannoolal et al. (2004, 2008); Moller et al. (2008) with estimated boiling points. At first sight, it seems unnecessarily complicated to have to estimate a boiling point for molecules for which vapor pressure data at room-temperature are available, while in the end one is only interested to estimate vapor pressures for ambient conditions. This is a drawback that direct estimation methods (Pankow and Asher, 2008; Capouet and Müller, 2006) do not have. On the other hand, direct estimation of vapor pressure at a given temperature is much more difficult than estimation of a boiling temperature for a given pressure (see discussion phase of this work). Hence the estimation of a normal boiling point is a convenient starting point to estimate a vapor pressure, even if this boiling point is far above the temperature of interest.

One of the methods (Moller et al., 2008) showed anomalous behaviour for certain polyfunctional compounds. This is not simply due to some bad parameters but rather due to the mathematical formulation of the method. Ultimately, this touches the problem of how the contributions of the functional groups to the vapor pressure should scale for highly polyfunctional molecules. Group interaction terms are, in essence, corrections to the group contributions obtained for monofunctional molecules. In the formulation of Nannoolal et al. (2008) these corrections become negligible for highly polyfunctional molecules, while for the method of Moller et al. (2008) they become dominant and scale agressively. The truth is probably in the middle of both extremes, with group interactions being significant, but not dominant compared to the basic group contributions. Adressing this problem is essential if one wants to predict reliably the vapor pressure of highly polyfunctional compounds. Another problem of the group-interaction approach of the methods of Nannoolal et al. (2008) and of Moller et al. (2008) is the large number of parameters necessary, while data for polyfunctional molecules are scant and typically less precise. Hence a more concise approach to the problem of group interactions seems to be justified.

The method MY-JR (Myrdal and Yalkowsky, 1997; Joback and Reid, 1987) yields generally the lowest vapor pressure of all considered methods. Given the known overprediction of high boiling points by JR (Stein and Brown, 1994), this method is not recommended.

Assuming that partitioning to the aerosol phase follows Eq. (1), the precise vapor pressure method will determine to a great extent the amount of aerosol simulated. This was illustrated by Barley and McFiggans (2010) and by Ceulemans et al. (2010). In this last study, BOREAM was used to sim- ulate a wide range of $\alpha$-pinene dark ozonolysis smog chamber experiments, and among other variables, also the vapor pressure method was varied in the simulation of the experiments of Pathak et al. (2007). The methods CM Capouet and Müller (2006) and Nan-Nan (Nannoolal et al., 2004, 2008) gave results closest to the experiments. SIMPOL (Pankow and Asher, 2008) overpredicted aerosol amounts, while MYNan (Myrdal and Yalkowsky, 1997; Nannoolal et al., 2004) underpredicted aerosol amounts considerably ${ }^{2}$. Of course, this does not necessarily imply that CM and Nan-Nan are the "best", as large uncertainties exist in the chemical mechanism. For example, in a very recent publication Camredon et al. (2010) found the best agreement with experimental aerosol yields of $\alpha$-pinene dark ozonolysis experiments using the method MY-JR (Myrdal and Yalkowsky, 1997; Joback and Reid, 1987), where MCMv3.1 (Jenkin et al., 1997; Jenkin, 2004) was the chemical mechanism, while MY-JR would lead to large overpredictions in aerosol yield when applied with BOREAM.

Acknowledgements. This work has been made possible by a grant of the Belgian Science Policy Office in the framework of the SSD program (2006-2010). The assistance of Lionel Carreira and coworkers in the use of the on-line batch mode of SPARC is gratefully acknowledged.

Edited by: G. McFiggans

\section{References}

Ambrose, D. and Walton, J.: Vapour pressures up to their critical temperatures of normal alkanes and 1-alkanols, Pure Appl. Chem., 61, 1395-1403, doi:10.1351/pac198961081395, 1989.

Balaban, A. T., Kier, L. B., and Joshi, N.: Correlations between chemical structure and normal boiling points of acyclic ethers, peroxides, acetals, and their sulfur analogs, J. Chem. Inf. Comput. Sci., 32, 237-244, doi:10.1021/ci00007a011, 1992.

Barley, M., Topping, D. O., Jenkin, M. E., and McFiggans, G.: Sensitivities of the absorptive partitioning model of secondary organic aerosol formation to the inclusion of water, Atmos. Chem. Phys., 9, 2919-2932, doi:10.5194/acp-9-2919-2009, 2009.

Barley, M. H. and McFiggans, G.: The critical assessment of vapour pressure estimation methods for use in modelling the formation of atmospheric organic aerosol, Atmos. Chem. Phys., 10, 749767, doi:10.5194/acp-10-749-2010, 2010.

Bruckmann, P. W. and Willner, H.: Infrared Spectroscopic Study Of Peroxyacetyl Nitrate (Pan) And Its Decomposition Products, Environ. Sci. Technol., 17, 352-357, 1983.

Camredon, M. and Aumont, B.: Assessment of vapor pressure estimation methods for secondary organic aerosol modeling, Atmos. Environ., 40, 2105-2116, doi:10.1016/j.atmosenv.2005.11.051, 2006.

\footnotetext{
${ }^{2}$ The methods of Joback and Reid (1987), of Moller et al. (2008) and of Hilal et al. (2003) were not considered in that work, as vapor pressure was not central in that work and because of the problems encountered with the first two methods.
} 
Camredon, M., Hamilton, J. F., Alam, M. S., Wyche, K. P., Carr, T., White, I. R., Monks, P. S., Rickard, A. R., and Bloss, W. J.: Distribution of gaseous and particulate organic composition during dark $\alpha$-pinene ozonolysis, Atmos. Chem. Phys., 10, 2893-2917, doi:10.5194/acp-10-2893-2010, 2010.

Capouet, M. and Müller, J.-F.: A group contribution method for estimating the vapour pressures of $\alpha$-pinene oxidation products, Atmos. Chem. Phys., 6, 1455-1467, doi:10.5194/acp-6-14552006, 2006.

Capouet, M., Müller, J.-F., Ceulemans, K., Compernolle, S., Vereecken, L., and Peeters, J.: Modeling aerosol formation in alpha-pinene photooxidation experiments, J. Geophys. Res., 113, D02308, doi:10.1029/2007JD008995, 2008.

Carreira, L. A., Hilal, S., and Karickhoff, S. W.: Estimation of chemical reactivity parameters and physical properties of organic molecules using SPARC, in: Theoretical and Computational Chemistry, Quantitative Treatment of Solute/Solvent Interactions, edited by: Politzer, P. and Murray, J. S., Elsevier Publishers, 1, 291-353, 1994.

Ceulemans, K., Compernolle, S., Peeters, J., and Mller, J.-F.: Evaluation of a detailed model of secondary organic aerosol formation from [alpha]-pinene against dark ozonolysis experiments, Corrected Proof, doi:10.1016/j.atmosenv.2010.05.001, Atmos. Environ., in press, 2010.

Claeys, M., Iinuma, Y., Szmigielski, R., Surratt, J. D., Blockhuys, F., Van Alsenoy, C., Böge, O., Sierau, B., Gómez-González, Y., Vermeylen, R., Van der Veken, P., Shahgholi, M., Chan, A. W. H., Herrmann, H., Seinfeld, J. H., and Maenhaut, W.: Terpenylic Acid and Related Compounds from the Oxidation of $\alpha$ Pinene: Implications for New Particle Formation and Growth above Forests, Environ. Sci. Technol., 43, 6976-6982, 2009.

Compernolle, S., Ceulemans, K., and Müller, J.-F.: Influence of non-ideality on condensation to aerosol, Atmos. Chem. Phys., 9, 1325-1337, 2009,

http://www.atmos-chem-phys.net/9/1325/2009/.

Egerton, A. C., Emte, W., and Minkoff, G. J.: Some properties of organic peroxides, Discuss. Faraday Soc., 10, 278-282, 1951.

Engineering Sciences Data Unit Ltd: Vapour pressures and critical points of liquids. Aliphatic and aromatic ethers, item No 95016, vol. 2d(ii), ESDU International, London, UK, 1995.

Engineering Sciences Data Unit Ltd: Vapour pressures and critical points of liquids. XVIII: Additional esters of aliphatic carboxylic acids, item No 81003, vol. 2d(i), ESDU International, London, UK, 2001.

Hallquist, M., Wenger, J. C., Baltensperger, U., Rudich, Y., Simpson, D., Claeys, M., Dommen, J., Donahue, N. M., George, C., Goldstein, A. H., Hamilton, J. F., Herrmann, H., Hoffmann, T., Iinuma, Y., Jang, M., Jenkin, M. E., Jimenez, J. L., KiendlerScharr, A., Maenhaut, W., McFiggans, G., Mentel, T. F., Monod, A., Prévôt, A. S. H., Seinfeld, J. H., Surratt, J. D., Szmigielski, R., and Wildt, J.: The formation, properties and impact of secondary organic aerosol: current and emerging issues, Atmos. Chem. Phys., 9, 5155-5236, doi:10.5194/acp-9-5155-2009, 2009.

Hilal, S. H., Karickhoff, S. W., and Carreira, L. A.: Prediction of the vapor pressure boiling point, heat of vaporization and diffusion coefficient of organic compounds, QSAR Comb. Sci., 22, 565574, doi:10.1002/qsar.200330812, 2003.

Hilal, S. H., Karickhoff, S. W., and Carreira, L. A.: Prediction of the solubility, activity coefficient and liquid/liquid partition coefficient of organic compounds, QSAR Comb. Sci., 23, 709-720, doi:10.1002/qsar.200430866, 2004.

Jenkin, M. E.: Modelling the formation and composition of secondary organic aerosol from $\alpha$ - and $\beta$-pinene ozonolysis using MCM v3, Atmos. Chem. Phys., 4, 1741-1757, doi:10.5194/acp4-1741-2004, 2004.

Jenkin, M. E., Saunders, S. M., and Pilling, M. J.: The tropospheric degradation of volatile organic compounds: a protocol for mechanism development, Atmos. Environ., 31, 81-104, doi: 10.1016/S1352-2310(96)00105-7, 1997.

Joback, K. and Reid, R.: Estimation of Pure-Component Properties from Group-Contributions, Chem. Eng. Commun., 57, 233-243, 1987.

Kacmarek, A. J. and Solomon, I. J., and Lustig, M.: Preparation and Properties of Peroxyacetyl Nitrate, J. Inorg. and Nucl. Chem., 40, 574-576, 1978.

Marrero, J. and Gani, R.: Group-contribution based estimation of pure component properties, Fluid Phase Equilibr., 183-184, 183208, doi:10.1016/S0378-3812(01)00431-9, 2001.

Moller, B., Rarey, J., and Ramjugernath, D.: Estimation of the vapour pressure of non-electrolyte organic compounds via group contributions and group interactions, J. Mol. Liq., 143, 52-63, doi:10.1016/j.molliq.2008.04.020, 2008.

Myrdal, P. B. and Yalkowsky, S. H.: Estimating Pure Component Vapor Pressures of Complex Organic Molecules, Ind. Eng. Chem. Res., 36, 2494-2499, doi:10.1021/ie9502421, 1997.

Nannoolal, Y., Rarey, J., Ramjugernath, D., and Cordes, W.: Estimation of pure component properties: Part 1. Estimation of the normal boiling point of non-electrolyte organic compounds via group contributions and group interactions, Fluid Phase Equilibr., 226, 45-63, doi:10.1016/j.fluid.2004.09.001, 2004.

Nannoolal, Y., Rarey, J., and Ramjugernath, D.: Estimation of pure component properties: Part 3. Estimation of the vapor pressure of non-electrolyte organic compounds via group contributions and group interactions, Fluid Phase Equilibr., 269, 117-133, doi:10. 1016/j.fluid.2008.04.020, 2008.

Pankow, J. F.: An absorption model of gas/particle partitioning of organic compounds in the atmosphere, Atmos. Environ., 28, 185, doi:10.1016/1352-2310(94)90093-0, 1994.

Pankow, J. F. and Asher, W. E.: SIMPOL.1: a simple group contribution method for predicting vapor pressures and enthalpies of vaporization of multifunctional organic compounds, Atmos. Chem. Phys., 8, 2773-2796, doi:10.5194/acp-8-27732008, 2008.

Pathak, R. K., Stanier, C. O., Donahue, N. M., and Pandis, S. N.: Ozonolysis of alpha-pinene at atmospherically relevant concentrations: Temperature dependence of aerosol mass fractions (yields), J. Geophys. Res., 112, D03201, doi:10.1029/ 2006JD007436, 2007.

Poling, B. E., Prausnitz, J. M., and O'Connell, J. P.: The properties of gases and liquids, McGraw-Hill, New York, USA, 5 edn., 2001.

Sanchez, J. and Myers, T. N.: Peroxides and Peroxide Compounds, Organic Peroxides, vol. 18 of Kirk-Othmer Encyclopedia of Chemical Technology, Wiley, 4 edn., doi:10.1002/0471238961. 1518070119011403.a01, 2000.

Stein, S. E. and Brown, R. L.: Estimation of normal boiling points from group contributions, J. Chem. Inf. Comp. Sci., 34, 581-587, 
doi:10.1021/ci00019a016, 1994.

Szmigielski, R., Surratt, J. D., Gómez-González, Y., Van der Veken, P., Kourtchev, I., Vermeylen, R., Blockhuys, F., Jaoui, M., Kleindienst, T. E., Lewandowski, M., Offenberg, J. H., Edney, E. O., Seinfeld, J. H., Maenhaut, W., and Claeys, M.: 3-methyl-1,2,3butanetricarboxylic acid: An atmospheric tracer for terpene secondary organic aerosol, Geophys. Res. Lett., 34, L24811, doi: 10.1029/2007GL031338, 2007.
Vereecken, L., Müller, J.-F., and Peeters, J.: Low-volatility poly-oxygenates in the $\mathrm{OH}$-initiated atmospheric oxidation of $\alpha$-pinene: impact of non-traditional peroxyl radical chemistry, Phys. Chem. Chem. Phys., 9, 5241-5248, doi:10.1039/ b708023a, 2007. 